\title{
Guards and Culprits in the Endoplasmic Reticulum: Glucolipotoxicity and $\beta$-Cell Failure in Type II Diabetes
}

\author{
Udayakumar Karunakaran, Han-Jong Kim, Joon-Young Kim, and In-Kyu Lee \\ Departments of Internal Medicine, and Biochemistry and Cell Biology, Research Institute of Aging and Metabolism and \\ World Class University Program, Kyungpook National University School of Medicine, Daegu 700-721, Republic of Korea \\ Correspondence should be addressed to In-Kyu Lee, leei@knu.ac.kr
}

Received 15 May 2011; Revised 2 August 2011; Accepted 3 August 2011

Academic Editor: Ki-Up Lee

Copyright () 2012 Udayakumar Karunakaran et al. This is an open access article distributed under the Creative Commons Attribution License, which permits unrestricted use, distribution, and reproduction in any medium, provided the original work is properly cited.

\begin{abstract}
The endoplasmic reticulum (ER) is a cellular organelle responsible for multiple important cellular functions including the biosynthesis and folding of newly synthesized proteins destined for secretion, such as insulin. The ER participates in all branches of metabolism, linking nutrient sensing to cellular signaling. Many pathological and physiological factors perturb ER function and induce ER stress. ER stress triggers an adaptive signaling cascade, called the unfolded protein response (UPR), to relieve the stress. The failure of the UPR to resolve ER stress leads to pathological conditions such as $\beta$-cell dysfunction and death, and type II diabetes. However, much less is known about the fine details of the control and regulation of the ER response to hyperglycemia (glucotoxicity), hyperlipidemia (lipotoxicity), and the combination of both (glucolipotoxicity). This paper considers recent insights into how the response is regulated, which may provide clues into the mechanism of ER stress-mediated $\beta$-cell dysfunction and death during the progression of glucolipotoxicity-induced type II diabetes.
\end{abstract}

\section{Introduction}

Type II diabetes is a heterogeneous syndrome resulting from progressive impairment of $\beta$-cell insulin secretion and insulin resistance in target tissues. Prevalence of type II diabetes, in which the body attempts to compensate for insulin resistance by augmenting insulin secretion, has increased because of the rising rate of obesity [1]. However, it is increasingly clear that pancreatic $\beta$-cell dysfunction also contributes to type II diabetes [2]. Healthy pancreatic $\beta$-cells display a dramatic response to nutrients and to obesity-associated insulin resistance through hypersecretion of insulin to maintain energy homeostasis. But, in type II diabetes, $\beta$-cells are unable to sustain a compensatory response, leading to $\beta$-cell dysfunction and death [3]. Although the cause of the metabolic deterioration is unknown, several hypotheses have been proposed, including mitochondrial dysfunction, oxidative stress, ER stress, hyperglycemia (glucotoxicity), dyslipidemia (lipotoxicity), and the combination of both (glucolipotoxicity) [4-7].

Recent studies have suggested that elevated glucose, along with circulating free fatty acids (FFAs), and particularly those originating from intra-abdominal fat stores are the major culprits in insulin resistance and $\beta$-cell dysfunction $[6,7]$. The chronic hyperglycemia and hyperlipidemia cause combined, detrimental effects defined as glucolipotoxicity on $\beta$-cell function and survival [7]. However, the underlying molecular and cellular mechanisms by which glucolipotoxicity contributes to $\beta$-cell dysfunction and death in type II diabetes remain under debate. A recent observation based on experimental, clinical, and genetic evidence suggests that the endoplasmic reticulum (ER) may be responsible for the molecular mechanisms of glucolipotoxicity contributing to $\beta$-cell dysfunction in type II diabetes $[8,9]$. In this paper, we discuss the involvement of ER in glucolipotoxicity-induced $\beta$-cell dysfunction and death along with the involvement of mitochondria.

\section{ER Stress Response}

Pancreatic $\beta$-cells display a marked response to nutrient signals through balance between the anabolic hormone insulin and the catabolic hormone glucagon, which are used 
to maintain energy homeostasis. To mount an appropriate response, pancreatic $\beta$-cells require suitable sensors and signaling molecules, which integrate these signals to modulate insulin secretion to maintain homeostasis.

The ER is an integral contributor to protein synthesis, folding, maturation, trafficking, and degradation, and it may be an ideal site for nutrient sensation at the subcellular level [10]. The quality control machinery of the ER operates via specialized proteins and a specific chemical environment to ensure proper folding and processing of secretory proteins, and degradation of misfolded/unfolded proteins, including insulin, to maintain glucose homeostasis. However, overloading this machinery causes the more accumulation of misfolded/unfolded proteins in the ER and reduces the quality and quantity of ER, leading to ER stress [11]. To cope with this condition, cells activate an adaptive system linking the ER lumen with the cytoplasm and nucleus called the unfolded protein response (UPR). The UPR restores ER homeostasis, by attenuating global protein translation to decrease the protein overload and by increasing the expression of genes that induce protein folding and also promote ER-associated protein degradation (ERAD) to remove misfolded proteins [12].

The three branches of the UPR are mediated by the ER-membrane associated proteins PERK (protein kinase Rlike ER kinase), IRE1 $\alpha$ (Inositol requiring enzyme 1 ), and ATF6 (activating transcription factor 6). Under unstressed conditions, these three proteins are held by the abundant ER chaperone Bip/glucose-regulated protein 78 (GRP78) at the N-terminal domains of PERK and IRE $1 \alpha$ and at the carboxyl terminal of ATF6, preventing their aggregation and rendering them inactive [13]. Under ER stress conditions, PERK is autophosphorylated and in turn phosphorylates serine 51 of eukaryotic translation initiation factor $2 \alpha$ (eif $2 \alpha$ ), rendering it unable to efficiently initiate translation, leading to global inhibition of protein synthesis and at the same time inducing translation of the transcription factor ATF4. ATF4 protein translocates to the nucleus and upregulates ER stress target genes, including C/EBP homologous protein (CHOP) and downstream growth arrest and DNA damage-inducible protein (GADD34) that acts as a nonenzymatic cofactor for protein phosphatase-1 (PP-1), leading to eif $2 \alpha$ dephosphorylation for translational recovery $[14,15]$.

Under ER stress condition, activation of ATF6 involves the dissociation of Bip/GRP78 from its luminal domain and translocation to the Golgi for proteolytic processing where it is cleaved into its active form, which translocates into the nucleus to induce chaperon protein genes such as Bip/GRP78, GPR94, and calreticulin to enhance protein folding [16]. IRE1 $\alpha$, the third ER stress sensor, is a type 1 transmembrane protein with endoribonuclease activity. Similar to PERK, IRE $1 \alpha$ is autophosphorylated in response to accumulation of misfolded/unfolded proteins in the ER. Once activated, IRE $1 \alpha$ catalyzes the splicing of X-boxbinding protein 1 (XBP-1) mRNA, leading to translation of the active transcription factor XBP-1 that induces the expression of genes required for protein folding, ER to Golgi transport, and endoplasmic-reticulum-associated protein degradation (ERAD) [17].

\section{UPR under Glucolipoadaptation in $\beta$-Cells}

Adaptation to metabolic changes requires regulation and coordination of many homeostatic systems, since the quality and quantity of available nutrients does not temporally match cellular needs. Acute exposure of $\beta$-cells to high glucose induces mild UPR signaling accompanied by phosphorylation and activation of IRE $1 \alpha$, leading to glucose-induced insulin biosynthesis [18]. Conversely, inactivation of IRE1 $\alpha$ signaling by siRNA or inhibition of IRE $1 \alpha$ phosphorylation hinders glucose-induced insulin biosynthesis, indicating that acute IRE $1 \alpha$ activation is required for proinsulin biosynthesis. Surprisingly, however, acute high glucose-induced IRE $1 \alpha$ was found not to splice the downstream target XBP-1, implying that IRE $\alpha$-mediated XBP-1 splicing is not essential for proinsulin biosynthesis.

Another study suggested that transient high glucose upregulates the ER resident protein oxidoreductase $1 \alpha$ $(\mathrm{ERO} 1 \alpha)$, an activator of protein disulfide isomerase (PDI), which plays an important role in disulfide bond formation. Thus, ERO1 $\alpha$ may activate insulin biosynthesis by enhancing disulfide bond formation in proinsulin in the ER [19]. Rutkowski and Kaufman suggested that eif $\alpha$ phosphorylation limits proinsulin mRNA translation under low-glucose condition [10]. However, paradoxically, eif2a phosphorylation seems to be needed to upregulate proinsulin mRNA translation to compromise the uncontrolled insulin translation in response to physiologic intermittent high glucose levels [11]. Steady-state eif $2 \alpha$ phosphorylation in glucose-induced protein translation is short, and it can be rapidly dephosphorylated by physiological stimuli via a signaling pathway that activates GADD34 and PPI [20].

In parallel with glucose, saturated and unsaturated FFAs elicit quantitatively and qualitatively different ER stress signaling in $\beta$-cells. Most investigators have employed palmitate or oleate as the fatty acids of choice because they represent the major species to which $\beta$-cells might be exposed in vivo [21]. However, considering the specific effects of fatty acids on $\beta$-cell viability, palmitate is more potent than oleate in triggering ER stress in clonal and primary rodent $\beta$-cells, and in human islets [22-24]. Exposure to long-chain FFAs within the physiologic range can directly stimulate insulin secretion through changes in ER calcium $\left(\mathrm{Ca}^{2+}\right)$ handling [25]. ER is thought to be the main dynamic intracellular $\mathrm{Ca}^{2+}$ storage compartment in $\beta$-cells. Palmitate causes increases in phosphorylation of the PERK branch and IRE1 $\alpha$-activated spliced form of XBP-1, but the effects of oleate are much less significant [26]. The marked activation of PERK-eif $2 \alpha$ phosphorylation by palmitate leads to the induction of ATF4 and CHOP expression, which results in inhibition of protein translation [27]. Thus, FFAs differentially regulate the UPR response under physiological conditions to maintain homeostasis. Growing evidence supports the notion that early activation of UPR signaling improves $\beta$-cell homeostasis in glucolipoadaptation. 


\section{ER Stress under Glucolipotoxicity}

Accumulating evidence suggests that glucolipotoxicity contributes to $\beta$-cell dysfunction during the development of type II diabetes. Chronic exposure of $\beta$-cells to supraphysiological levels of glucose or FFAs has been shown to be cytotoxic and causes $\beta$-cell dysfunction and failure [28-30]. Briaud et al. have provided evidence that lipotoxicity occurs in the presence of concomitantly elevated levels of glucose [31]. Several mechanisms have been proposed for glucolipotoxicityinduced $\beta$-cell dysfunction and failure, such as increased ROS, ceramide, and nitric oxide levels, and mitochondrial perturbations [32-34]. Recent evidence suggests that ER stress is linked to insulin resistance in diabetes and also expansion of ER was detected in $\beta$-cells from type II diabetic patients $[35,36]$. Furthermore, increased expression of ER stress markers has been demonstrated in $\mathrm{db} / \mathrm{db}$ mouse islets and $\beta$-cells of type 2 diabetes patients $[23,36]$. These findings suggest that ER stress may be a pathophysiological event responsible for $\beta$-cell dysfunction and failure in type II diabetes.

Endoplasmic reticulum $\mathrm{Ca}^{2+}$ is an important signaling molecule in the $\beta$-cell, and fluctuations in $\mathrm{Ca}^{2+}$ levels in the ER can affect many functions of the endoplasmic reticulum, including protein synthesis, processing, and interchaperone interactions [37]. However, experimental data suggest that saturated and, to a lesser extent, unsaturated FFAs, trigger the ER stress response through depletion of $\mathrm{ER} \mathrm{Ca}^{2+}$ stores $[26,38,39]$. Several discrepancies appear in studies of FFAinduced $\mathrm{ER} \mathrm{Ca}^{2+}$ depletion, but the mechanism appears to be similar to the direct effects on sarcoplasmic-endoplasmic reticulum $\mathrm{Ca}^{2+}$ ATPase-2b (SERCA) pump activity [39]. ER $\mathrm{Ca}^{2+}$ depletion affects protein folding in the ER, because high luminal $\mathrm{Ca}^{2+}$ is essential for proteolytic processing and folding of proinsulin [37]. In addition, palmitate causes rapid redistribution and degradation of carboxypeptidase $\mathrm{E}$ (CPE) by depleting ER $\mathrm{Ca}^{2+}$. CPE is a soluble membrane-bound enzyme in secretory granules involved in insulin processing. Degradation of CPE by palmitate was found to cause accumulation of unprocessed proinsulin in the secretory pathway [40]. Along with depletion of $\mathrm{ER} \mathrm{Ca}^{2+}$, palmitate also hampers ER-to-Golgi trafficking, as monitored using a temperature-sensitive vesicular stomatitis virus $G$ protein, contributing to the accumulation of misfolded proteins and impacting ER integrity and function [41].

\section{Unfolded Death Response}

As described above, elevated glucose and FFA act synergistically in causing pleiotropic effects leading to $\beta$-cell decompensation and apoptosis during type II diabetes. It has been shown that palmitate induces $\beta$-cell dysfunction and apoptosis via activation of ER stress. This activates the UPR to restore normal ER function; when the UPR fails to adequately restore ER function, it turns on signaling pathways leading to apoptosis $[42,43]$. The ER-localized protein Bip/GRP78 is a multifunctional chaperone and sensor of protein misfolding and controls activation of the UPR response in ER stress. Bip/GRP78 is upregulated during
ER stress; overexpression of Bip/GRP78 under hyperglycemic conditions improves insulin levels and $\beta$-cell function [44]. In mouse MIN6 cells, Bip/GRP78 overexpression reduces ER stress and partially protects cells against fatty acidinduced apoptosis [23]. C/EBPbeta, a CCAAT/enhancerbinding protein (C/EBP) family basic leucine zipper (bZip) transcription factor, was found to be increased in diabetic islets and to block the induction of Bip/GRP78 due to the suppressed transactivation of ATF6 $\alpha$, thereby increasing the vulnerability of $\beta$-cells to ER stress [45]. However, the role of Bip/GRP78 under palmitate-induced ER stress is under debate. In BRIN-BD11 cells, palmitate exposure does not induce Bip/GRP78 [46]. These discrepancies may be dependent on cell type, and a direct comparison between studies would be required to understand the exact phenomenon that happened under these experimental conditions.

As with Bip/GRP78, the effects of palmitate on the ATF6 $\alpha$ pathway in $\beta$-cells are also controversial. Transient transfection of INS- 1 cells with HA-tagged ATF6 $\alpha$ revealed that ATF $6 \alpha$ protein was distributed around the nucleus and in the periphery of the cell in response to palmitate without induction of Bip/GRP78, but not in control or oleate-treated cells [47]. By contrast, Kharroubi et al. showed induction of the ATF6 $\alpha$-GPR78 signaling pathway by palmitate in INS1 cells [48]. Recent evidence has also shown that missense mutations and polymorphisms within ATF $6 \alpha$ may be linked to type II diabetes $[49,50]$. Therefore, further studies are in need to delineate the exact ATF6 $\alpha$ signaling pathways induced by palmitate in $\beta$-cell failure.

By contrast, mice with a PERK deletion develop diabetes within a few weeks of birth due to progressive $\beta$-cell loss, highlighting the importance of the PERK-mediated ER stress response in the regulation of $\beta$-cell function and survival [51]. Like other ER sensors, PERK is maintained in an inactive state by binding to Bip/GRP78. Once activated, PERK autophosphorylates and catalyzes the phosphorylation of eif $2 \alpha[52,53]$. This results in a general attenuation of translation. Several studies have demonstrated that palmitate and, to a lesser extent, oleate activate rapid phosphorylation of the PERK by depletion of ER calcium leading to phosphorylation of eif $2 \alpha$, resulting in an overall decrease in translation, but increased translation of selected proteins including ATF3, ATF4, and CHOP [23, 39, 47, 54]. Induction of ATF4 by upstream PERK-eif2 $\alpha$ leads to the induction of CHOP via binding of ATF4 to the C/EBP-ATF binding site in the $\mathrm{CHOP}$ promoter [55]. Induction of ATF3, a proapoptotic protein, by palmitate leads to $\beta$-cell apoptosis [56]. In addition, it has been shown that ATF3 downregulates the expression of IRS-2 in $\beta$-cells [57]. By contrast, knockdown of ATF3 was found to increase palmitate-induced apoptosis instead of protecting against apoptosis [56]. Recently, Zmuda et al. showed that ATF3 knockout mice fed a high-fat diet for 12 weeks had significantly reduced serum insulin levels without insulin sensitivity being affected and without $\beta$ cell apoptosis being induced [58]. So far, the downstream targets of ATF3 in $\beta$-cells are not well known and further investigation is needed to clarify these unexpected findings.

Expression of CHOP induced by palmitate induces cell death through transcriptional regulation of survival and 
death effectors. CHOP was found to be localized in the nucleus as opposed to the cytoplasm in pancreatic sections from diabetic patients, suggesting that CHOP nuclear translocation is a discrete and necessary step for apoptosis induction [59]. CHOP also downregulates the expression of the antiapoptotic protein Bcl-2 and increases cellular reactive oxygen species, which likely contribute to ER stressassociated cell death [60]. CHOP also upregulates expression of ERO $1 \alpha$, an ER oxidase, causing hyperoxidizing conditions in the ER leading to apoptosis $[61,62]$.

Growing evidence shows that the IRE1 $\alpha$-XBP- 1 pathway is activated in $\beta$-cells by palmitate treatment, but that it is less sensitive to the monounsaturated fatty acid oleate $[46,47,54]$. Oleate can efficiently counteract palmitateinduced XBP-1 mRNA splicing, and knockdown of XBP-1 was shown to potentiate oleate- but not palmitate-mediated $\beta$-cell apoptosis, suggesting differential activation of proand antiapoptotic signals by downstream of IRE1 $\alpha$ [63]. In this regard, IRE $1 \alpha$ recruits the adaptor protein TNF receptor-associated factor 2 (TRAF2) to the ER membrane, leading to activation of JNK and downstream proapoptotic signaling [64]. In rodent $\beta$-cells, the association of IRE $1 \alpha$ and TRAF2 contributes to ER-triggered apoptosis $[65,66]$. Increased levels of saturated FFAs lead to JNK activation, IRS1 and IRS2 ser/thr phosphorylation, and downregulation of insulin signaling and gene expression [67]. Furthermore, inactivation of JNK in $\beta$-cells prevents palmitate-induced inhibition of insulin gene expression [68]. In addition, blockade of palmitate-induced activation of JNK using a JNK inhibitor partially protected $\beta$-cells from the effects of palmitate [64]. However, the downstream mechanism by which JNK leads to apoptosis is not clear, and this may be mediated via caspase activation, which is described in the next section (Figure 1).

\section{ER is Linked to Mitochondria to Induce Apoptosis}

The ER and mitochondria are capable of modifying their structure and function in response to changing environmental challenges. These two organelles form a highly dynamic interconnected network for activating apoptosis [69]. However, the regulatory mechanisms, which determine cell status leading to cell survival or cell death in response to ER stress, have not been well established. Mitochondria have a heterogeneous shape among different cell types and their ability to effectively function is influenced by their dynamic behavior. Interestingly, mitochondrial shape and morphology are determined by two dynamically opposed processes: fusion and fission. Ablation of both fusion and fission produces a profound effect on the progression of cells to apoptosis [70]. It has been shown that the mitochondria of $\beta$-cells from Zucker diabetic rats are fragmented, suggesting an imbalance in the regulation of mitochondrial fusion and fission [71]. Under normal conditions, mitochondria in $\beta$ cells continuously undergo fusion and fission and these interactions may function to negate the detrimental effects of long-term exposure of $\beta$-cells to palmitate under highglucose conditions, causing mitochondrial fragmentation and impairing network dynamics by abolishing fusion and fission activity. However, in the absence of palmitate, high glucose does not affect mitochondrial architecture [72].

It has been clearly demonstrated that apoptosis induction leads to fragmentation of the mitochondrial network. Moreover, inhibition of mitochondrial fission by Fis1, an outer mitochondrial membrane fission protein that determines the frequency of mitochondrial fission, reduced apoptosis in $\beta$-cells [72]. This has been questioned by another study, which ruled out the possibility that fragmentation occurs early in the cell death pathway [73]. These conflicting results may be reconciled by the fact that mitochondria are able to receive different stress signals and integrate them. How, then, do high-fat glucose conditions promote mitochondrial fragmentation and apoptosis? It is assumable that crosstalk between the ER and mitochondria may determine cellular commitment to apoptosis through $\mathrm{Ca}^{2+}$. Exposure of $\beta$ cells to high-fat glucose conditions causes release of $\mathrm{Ca}^{2+}$ from the ER to the cytoplasm, leading to a rise in cytosolic $\mathrm{Ca}^{2+}$ concentration that reflects increased mitochondrial $\mathrm{Ca}^{2+}$ uptake. Increased mitochondrial $\mathrm{Ca}^{2+}$ uptake enhances local buffering capacity and release of proteins capable of apoptosis activation [74]. Subsequently, $\mathrm{Ca}^{2+}$ activates the phosphatase calcineurin, which dephosphorylates and inactivates dynamin-related protein 1 (Drp1), a master regulator of mitochondrial fission. Interestingly, inhibition of calcineurin activation partially prevented palmitate-induced apoptosis [75]. In addition, palmitate-induced activation of mitochondrial transition pores caused depolarization of the mitochondrial inner membrane and cytochrome c release into the cytosol, which stimulates the assembly of the apoptosome leading to activation of caspase-9, which, in turn, activates caspase-3, leading to DNA fragmentation and cell death $[63,64,76,77]$. Moreover, mitochondrial cytochrome $\mathrm{c}$ translocates to the ER, where it selectively binds to InsP3R, leading to a sustained rise in cytosolic $\mathrm{Ca}^{2+}$ [78].

In addition, the Bcl-2 family of proteins has a role in mediating ER stress-induced apoptosis. Under normal conditions, $\mathrm{Bcl}-2$ can bind and sequester $\mathrm{BH} 3$-only proteins, preventing these proteins from triggering oligomerization and activation of Bax and Bak [79]. Upon stimulation, Bax translocates from the cytosol to the mitochondria and oligomerizes with Bak, resulting in mitochondrial outer membrane permeabilization and release of cytochrome $\mathrm{c}$ into the cytosol $[80,81]$. Mcl-1, a member of the antiapoptotic Bcl-2 protein family, prevents Bax activation and translocation by sequestering factors contributing to Bax translocation [81]. Allagnat et al. recently demonstrated that, under lipotoxic conditions, Mcl-1 expression was downregulated in $\beta$-cells leading to translocation of Bax into mitochondria, cytochrome $c$ release, and caspase3 cleavage and apoptosis [82]. However, supporting this concept, another study has suggested the involvement of translationally controlled tumor protein (TCTP) with no sequence similarity to any other known protein. TCTP binds to antiapoptotic proteins in the Bcl-2 family, such as Mcl1 and Bcl-XL, and antagonizes apoptosis by enhancing the antiapoptotic actions of these proteins [83]. Diraison et 


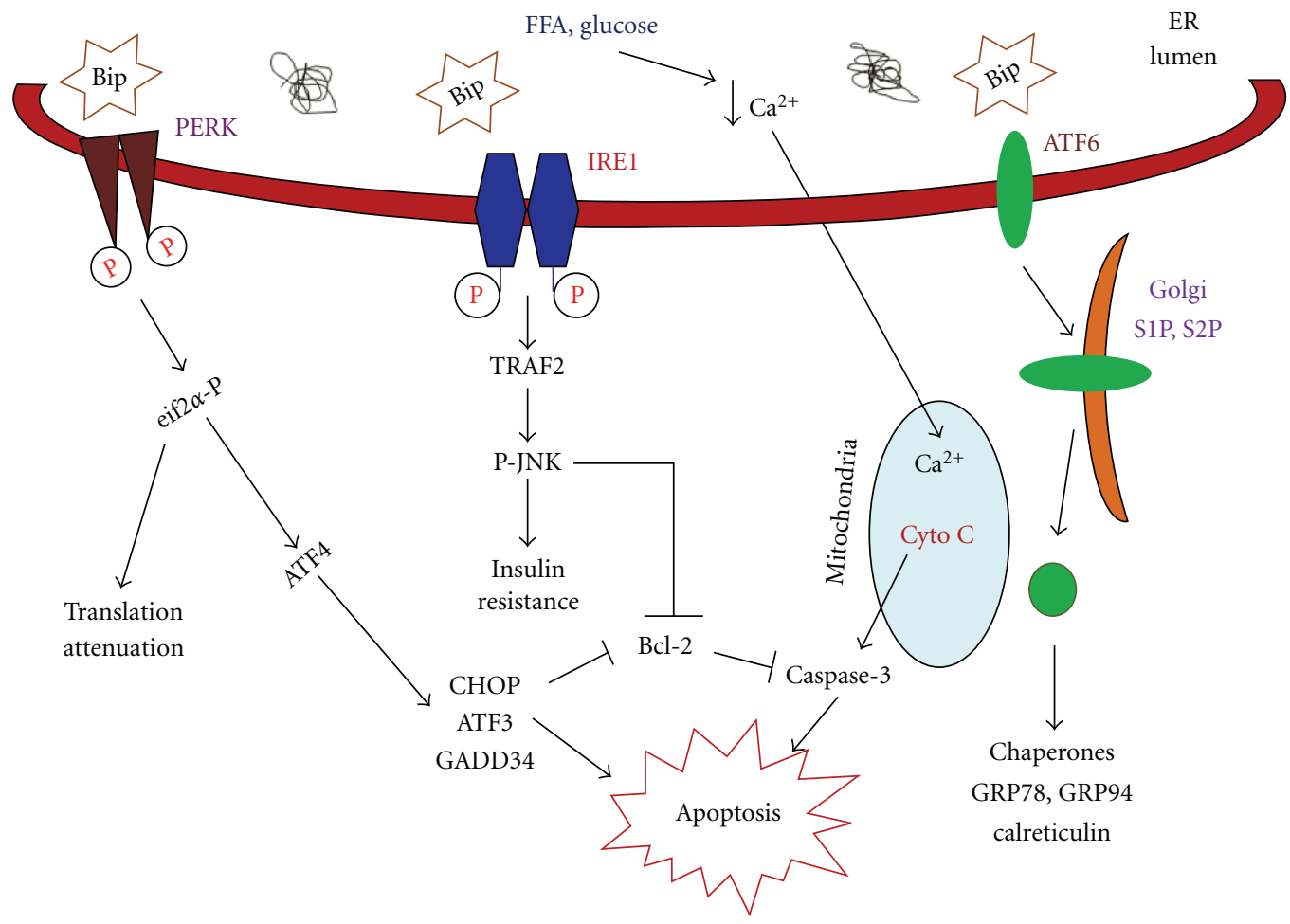

FIgURE 1: FFA-induced endoplasmic reticulum stress transduction and apoptosis in pancreatic $\beta$-cells, and its mechanisms; how FFA elicits $\beta$-cell apoptosis is discussed in detail in the text.

al. showed that, in $\beta$-cells, glucose regulates the expression of TCTP and its translocation from the cytosol to the nucleus by phosphorylation and glucose levels influence the sensitivity of $\beta$-cells to apoptosis. Palmitate treatment of $\beta$ cells decreased TCTP, resulting in increased $\beta$-cell death, and overexpression of TCTP prevented $\beta$-cell death. These authors also demonstrated that TCTP partially translocates to the mitochondrion in response to glucose. But it is not clear how glucose regulates TCTP translocation to various organelles and protects cells from apoptotic stimuli [84].

In addition, as described previously, FFA-induced activation of $\mathrm{CHOP}$ and JNK pathways decreased expression and increased the phosphorylation of $\mathrm{Bcl}-2$, respectively [63, 76, 85, 86]. Phosphorylated Bcl-2 also enhances $\mathrm{Ca}^{2+}$ efflux from the ER and increases $\mathrm{Ca}^{2+}$ uptake by mitochondria [87]. Indeed, overexpression of $\mathrm{Bcl}-2$ can influence the distribution of $\mathrm{Ca}^{2+}$ within the ER and mitochondria and can protect against apoptosis [88-90]. Together, these findings suggest the existence of a novel pathway involving the ER and mitochondria, through which these organelles orchestrate the regulation of death signals. In this complex scenario, further understanding of this link should give insights valuable for the identification of therapeutic targets to protect $\beta$-cell function and prevent type II diabetes.

\section{Therapeutic Agents Targeted to the ER}

ER stress has been found to be associated with obesity, insulin resistance, and type II diabetes. Therefore, agents that reduce ER stress are useful in treating obesity, peripheral insulin resistance, and hyperglycemia and type II diabetes. These agents reduce or prevent ER stress by improving the folding or processing capacity of the ER. Chemical chaperones such as PBA and TUDCA have been shown to regulate ER stress and improve insulin sensitivity in vivo [91]. In addition, salubrinal, a selective inhibitor of eif $2 \alpha$ dephosphorylation, has been proposed as a novel therapy for diabetes. Salubrinal blocks eif $2 \alpha$ dephosphorylation mediated by herpes simplex virus protein and inhibits viral replication [92]. But, in $\beta$-cells, selective inhibition of eif $2 \alpha$ was found to potentiate lipotoxicity [27].

A growing body of evidence suggests that glucagon-like peptide 1 (GLP-1) and its analogues ameliorate experimental diabetes and preserve $\beta$-cell mass, protecting $\beta$-cells from apoptosis [93-95]. Activation of GLP-1 receptor by exendin4 was shown to improve the survival of $\beta$-cells exposed to chemically induced ER stress via increased ATF4-CHOP expression. Interestingly, upon exposure to lipotoxic conditions, GLP-1 receptor activation prevented $\beta$-cell apoptosis by increasing cellular defense through the induction of Bip/GPR78 and the antiapoptotic protein junB [63].

Recently, in a search for novel therapeutic agents, plant-derived flavonoids were found to exhibit a broad spectrum of bioactivities. They display a remarkable array of biochemical and pharmacological actions, which may significantly affect the functions of various cellular systems [96]. Among flavonoids, methoxyflavonoids have beneficial hypolipidemic effects and suppress ER stress both in vivo 
and in vitro $[97,98]$. In addition, quercetin, a flavonoid found in many plants, protects $\beta$-cells from oxidative damage and preserves $\beta$-cell integrity $[99,100]$. Several studies have demonstrated that the isoflavone genistein, isolated from legumes, has antidiabetic effects presumably mediated by hypolipidemic effects, thereby increasing insulin sensitivity. Administration of genistein to animal and human islets increased islet proliferation, survival, and mass, mediated by activation of cAMP/PKA/ERK1/2 phosphorylation [101103]. To date, the beneficial activities of flavonoids have been attributed mainly to their antioxidant properties. Detailed studies are needed to reveal the mechanisms beyond antioxidant activity underlying the beneficial effects of flavonoids on the ER-mitochondrial connection in the apoptotic cascade.

\section{Conclusion}

It is known from experimental evidence that ER stress contributes to tissue dysfunction and damage caused by glucolipotoxicity in diabetes. However, the mechanisms underlying $\beta$-cell dysfunction and death in diabetes are complex. Understanding this complex scenario and the agents that modulate the ER stress response to $\beta$-cell resistance to lipotoxic stress could have considerable impact on the treatment of $\beta$-cell failure and type II diabetes. Thus, additional studies are required to determine the link between ER stress and $\beta$-cell failure. This may potentially lead to the development of novel therapeutics to prevent type II diabetes.

\section{Acknowledgments}

This work was supported by the grants from National Research Foundation of Korea (NRF) funded by the Korean Ministry of Education, Science and Technology (MEST) (nos. 2011-0027844 and 2011-0001026, World Class University program (R32-10064) and the Regional Core Research Program/Anti-aging and Well-being Research Center).

\section{References}

[1] S. E. Kahn, "The relative contributions of insulin resistance and beta-cell dysfunction to the pathophysiology of Type 2 diabetes," Diabetologia, vol. 46, no. 1, pp. 3-19, 2003.

[2] D. Porte, "Clinical importance of insulin secretion and its interaction with insulin resistance in the treatment of type 2 diabetes mellitus and its complications," Diabetes/Metabolism Research and Reviews, vol. 17, no. 3, pp. 181-188, 2001.

[3] J. L. Leahy, "Pathogenesis of type 2 diabetes mellitus," Archives of Medical Research, vol. 36, no. 3, pp. 197-209, 2005.

[4] P. Maechler and P. B. M. De Andrade, "Mitochondrial damages and the regulation of insulin secretion," Biochemical Society Transactions, vol. 34, part 5, pp. 824-827, 2006.

[5] K. G. Park, K. M. Lee, H. Y. Seo et al., "Glucotoxicity in the INS-1 rat insulinoma cell line is mediated by the orphan nuclear receptor small heterodimer partner," Diabetes, vol. 56, no. 2, pp. 431-437, 2007.

[6] M. Cnop, N. Welsh, J. C. Jonas, A. Jörns, S. Lenzen, and D. L. Eizirik, "Mechanisms of pancreatic $\beta$-cell death in type 1 and type 2 diabetes: many differences, few similarities," Diabetes, vol. 54, no. 2, pp. S97-S107, 2005.

[7] R. P. Robertson, J. Harmon, P. O. T. Tran, and V. Poitout, “ $\beta$ cell glucose toxicity, lipotoxicity, and chronic oxidative stress in type 2 diabetes," Diabetes, vol. 53, no. 1, pp. S119-S124, 2004.

[8] D. L. Eizirik, A. K. Cardozo, and M. Cnop, "The role for endoplasmic reticulum stress in diabetes mellitus," Endocrine Reviews, vol. 29, no. 1, pp. 42-61, 2008.

[9] H. Wang, G. Kouri, and C. B. Wollheim, "ER stress and SREBP-1 activation are implicated in B-cell glucolipotoxicity," Journal of Cell Science, vol. 118, no. 17, pp. 3905-3915, 2005.

[10] D. T. Rutkowski and R. J. Kaufman, "A trip to the ER: coping with stress," Trends in Cell Biology, vol. 14, no. 1, pp. 20-28, 2004.

[11] D. Scheuner, B. Song, E. McEwen et al., "Translational control is required for the unfolded protein response and in vivo glucose homeostasis," Molecular Cell, vol. 7, no. 6, pp. 11651176, 2001.

[12] M. Boyce and J. Yuan, "Cellular response to endoplasmic reticulum stress: a matter of life or death," Cell Death and Differentiation, vol. 13, no. 3, pp. 363-373, 2006.

[13] A. Bertolotti, Y. Zhang, L. M. Hendershot, H. P. Harding, and D. Ron, "Dynamic interaction of BiP and ER stress transducers in the unfolded-protein response," Nature Cell Biology, vol. 2, no. 6, pp. 326-332, 2000.

[14] C. Jousse, S. Oyadomari, I. Novoa et al., "Inhibition of a constitutive translation initiation factor $2 \alpha$ phosphatase, CReP, promotes survival of stressed cells," Journal of Cell Biology, vol. 163, no. 4, pp. 767-775, 2003.

[15] D. Ron, "Translational control in the endoplasmic reticulum stress response," Journal of Clinical Investigation, vol. 110, no. 10, pp. 1383-1388, 2002.

[16] K. Kokame, H. Kato, and T. Miyata, "Identification of ERSEII, a new cis-acting element responsible for the ATF6dependent mammalian unfolded protein response," Journal of Biological Chemistry, vol. 276, no. 12, pp. 9199-9205, 2001.

[17] K. J. Travers, C. K. Patil, L. Wodicka, D. J. Lockhart, J. S. Weissman, and P. Walter, "Functional and genomic analyses reveal an essential coordination between the unfolded protein response and ER-associated degradation," Cell, vol. 101, no. 3, pp. 249-258, 2000.

[18] K. L. Lipson, S. G. Fonseca, S. Ishigaki et al., "Regulation of insulin biosynthesis in pancreatic beta cells by an endoplasmic reticulum-resident protein kinase IRE1," Cell Metabolism, vol. 4, no. 3, pp. 245-254, 2006.

[19] B. P. Tu and J. S. Weissman, "Oxidative protein folding in eukaryotes: mechanisms and consequences," Journal of Cell Biology, vol. 164, no. 3, pp. 341-346, 2004.

[20] D. Vander Mierde, D. Scheuner, R. Quintens et al., "Glucose activates a protein phosphatase-1-mediated signaling pathway to enhance overall translation in pancreatic $\beta$-cells," Endocrinology, vol. 148, no. 2, pp. 609-617, 2007.

[21] G. V. Richieri and A. M. Kleinfeld, "Unbound free fatty acid levels in human serum," Journal of Lipid Research, vol. 36, no. 2, pp. 229-240, 1995.

[22] D. A. Cunha, P. Hekerman, L. Ladrière et al., "Initiation and execution of lipotoxic ER stress in pancreatic $\beta$-cells," Journal of Cell Science, vol. 121, no. 14, pp. 2308-2318, 2008.

[23] D. R. Laybutt, A. M. Preston, M. C. Åkerfeldt et al., "Endoplasmic reticulum stress contributes to beta cell apoptosis in type 2 diabetes," Diabetologia, vol. 50, no. 4, pp. 752-763, 2007. 
[24] L. Ladrière, M. Igoillo-Esteve, D. A. Cunha et al., "Enhanced signaling downstream of ribonucleic acid-activated protein kinase-like endoplasmic reticulum kinase potentiates lipotoxic endoplasmic reticulum stress in human islets," Journal of Clinical Endocrinology and Metabolism, vol. 95, no. 3, pp. 1442-1449, 2010.

[25] C. S. Olofsson, A. Salehi, C. Holm, and P. Rorsman, "Palmitate increases L-type $\mathrm{Ca}^{2+}$ currents and the size of the readily releasable granule pool in mouse pancreatic $\beta$-cells," Journal of Physiology, vol. 557, part 3, pp. 935-948, 2004.

[26] K. S. Gwiazda, T. L. B. Yang, Y. Lin, and J. D. Johnson, "Effects of palmitate on ER and cytosolic $\mathrm{Ca}^{2+}$ homeostasis in $\beta$-cells," American Journal of Physiology-Endocrinology and Metabolism, vol. 296, no. 4, pp. E690-E701, 2009.

[27] M. Cnop, L. Ladriere, P. Hekerman et al., "Selective inhibition of eukaryotic translation initiation factor $2 \alpha$ dephosphorylation potentiates fatty acid-induced endoplasmic reticulum stress and causes pancreatic $\beta$-cell dysfunction and apoptosis," Journal of Biological Chemistry, vol. 282, no. 6, pp. 3989-3997, 2007.

[28] E. P. Haber, H. M. Ximenes, J. Procopio, C. R. O. Carvalho, R. Curi, and A. R. Carpinelli, "Pleiotropic effects of fatty acids on pancreatic beta-cells," Journal of Cellular Physiology, vol. 194, pp. 1-12, 2002.

[29] M. Prentki and C. J. Nolan, "Islet $\beta$ cell failure in type 2 diabetes," Journal of Clinical Investigation, vol. 116, no. 7, pp. 1802-1812, 2006.

[30] R. H. Unger and Y. T. Zhou, "Lipotoxicity of $\beta$-cells in obesity and in other causes of fatty acid spillover," Diabetes, vol. 50, no. 1, pp. S118-S121, 2001.

[31] I. Briaud, J. S. Harmon, C. L. Kelpe, V. B. G. Segu, and V. Poitout, "Lipotoxicity of the pancreatic $\beta$-cell is associated with glucose-dependent esterification of fatty acids into neutral lipids," Diabetes, vol. 50, no. 2, pp. 315-321, 2001.

[32] R. Lupi, F. Dotta, L. Marselli et al., "Prolonged exposure to free fatty acids has cytostatic and pro-apoptotic effects on human pancreatic islets: Evidence that $\beta$-cell death is caspase mediated, partially dependent on ceramide pathway, and Bcl2 regulated," Diabetes, vol. 51, no. 5, pp. 1437-1442, 2002.

[33] M. Shimabukuro, M. Ohneda, Y. Lee, and R. H. Unger, "Role of nitric oxide in obesity-induced $\beta$ cell disease," Journal of Clinical Investigation, vol. 100, no. 2, pp. 290-295, 1997.

[34] I. Maestre, J. Jordán, S. Calvo et al., "Mitochondrial dysfunction is involved in apoptosis induced by serum withdrawal and fatty acids in the $\beta$-cell line INS-1," Endocrinology, vol. 144, no. 1, pp. 335-345, 2003.

[35] Y. Nakatani, H. Kaneto, D. Kawamori et al., "Involvement of endoplasmic reticulum stress in insulin resistance and diabetes," Journal of Biological Chemistry, vol. 280, no. 1, pp. 847-851, 2005.

[36] P. Marchetti, M. Bugliani, R. Lupi et al., "The endoplasmic reticulum in pancreatic beta cells of type 2 diabetes patients," Diabetologia, vol. 50, no. 12, pp. 2486-2494, 2007.

[37] P. C. Guest, E. M. Bailyes, and J. C. Hutton, "Endoplasmic reticulum $\mathrm{Ca}^{2+}$ is important for the proteolytic processing and intracellular transport of proinsulin in the pancreatic $\beta$ cell," Biochemical Journal, vol. 323, no. 2, pp. 445-450, 1997.

[38] O. Remizov, R. Jakubov, M. Düfer et al., "Palmitate-induced $\mathrm{Ca}^{2+}$-signaling in pancreatic beta-cells," Molecular and Cellular Endocrinology, vol. 212, no. 1-2, pp. 1-9, 2003.

[39] H. Shapiro, S. Shachar, I. Sekler, M. Hershfinkel, and M. D. Walker, "Role of GPR40 in fatty acid action on the $\beta$ cell line INS-1E," Biochemical and Biophysical Research Communications, vol. 335, no. 1, pp. 97-104, 2005.
[40] K. D. Jeffrey, E. U. Alejandro, D. S. Luciani et al., "Carboxypeptidase E mediates palmitate-induced $\beta$-cell ER stress and apoptosis," Proceedings of the National Academy of Sciences of the United States of America, vol. 105, no. 24, pp. 8452-8457, 2008.

[41] A. M. Preston, E. Gurisik, C. Bartley, D. R. Laybutt, and T. J. Biden, "Reduced endoplasmic reticulum (ER)-to-Golgi protein trafficking contributes to ER stress in lipotoxic mouse beta cells by promoting protein overload," Diabetologia, vol. 52, no. 11, pp. 2369-2373, 2009.

[42] W. El-Assaad, J. Buteau, M. L. Peyot et al., "Saturated fatty acids synergize with elevated glucose to cause pancreatic $\beta$ cell death," Endocrinology, vol. 144, no. 9, pp. 4154-4163, 2003.

[43] M. Prentki, E. Joly, W. El-Assaad, and R. Roduit, "MalonylCoA signaling, lipid partitioning, and glucolipotoxicity: role in $\beta$-cell adaptation and failure in the etiology of diabetes," Diabetes, vol. 51, no. 3, pp. S405-S413, 2002.

[44] L. Zhang, E. Lai, T. Teodoro, and A. Volchuk, "GRP78, but not protein-disulfide isomerase, partially reverses hyperglycemia-induced inhibition of insulin synthesis and secretion in pancreatic $\beta$-cells," Journal of Biological Chemistry, vol. 284, no. 8, pp. 5289-5298, 2009.

[45] T. Matsuda, Y. Kido, S. I. Asahara et al., "Ablation of C/EBP $\beta$ alleviates ER stress and pancreatic $\beta$ cell failure through the GRP78 chaperone in mice," Journal of Clinical Investigation, vol. 120, no. 1, pp. 115-126, 2010.

[46] E. Diakogiannaki, H. J. Welters, and N. G. Morgan, "Differential regulation of the endoplasmic reticulum stress response in pancreatic $\beta$-cells exposed to long-chain saturated and monounsaturated fatty acids," Journal of Endocrinology, vol. 197, no. 3, pp. 553-563, 2008.

[47] E. Karaskov, C. Scott, L. Zhang, T. Teodoro, M. Ravazzola, and A. Volchuk, "Chronic palmitate but not oleate exposure induces endoplasmic reticulum stress, which may contribute to INS-1 pancreatic $\beta$-cell apoptosis," Endocrinology, vol. 147, no. 7, pp. 3398-3407, 2006.

[48] I. Kharroubi, L. Ladrière, A. K. Cardozo, Z. Dogusan, M. Cnop, and D. L. Eizirik, "Free fatty acids and cytokines induce pancreatic $\beta$-cell apoptosis by different mechanisms: role of nuclear factor- $\kappa \mathrm{B}$ and endoplasmic reticulum stress," Endocrinology, vol. 145, no. 11, pp. 5087-5096, 2004.

[49] F. Thameem, V. S. Farook, C. Bogardus, and M. Prochazka, "Association of amino acid variants in the activating transcription factor 6 gene (ATF6) on 1q21-q23 with type 2 diabetes in Pima Indians," Diabetes, vol. 55, no. 3, pp. 839842, 2006.

[50] S. J. R. Meex, M. M. J. Van Greevenbroek, T. A. Ayoubi et al., "Activating transcription factor 6 polymorphisms and haplotypes are associated with impaired glucose homeostasis and type 2 diabetes in Dutch Caucasians," Journal of Clinical Endocrinology and Metabolism, vol. 92, no. 7, pp. 2720-2725, 2007.

[51] H. P. Harding, H. Zeng, Y. Zhang et al., "Diabetes mellitus and exocrine pancreatic dysfunction in Perk-/- mice reveals a role for translational control in secretory cell survival," Molecular Cell, vol. 7, no. 6, pp. 1153-1163, 2001.

[52] P. Zhang, B. McGrath, S. Li et al., "The PERK eukaryotic initiation factor $2 \alpha$ kinase is required for the development of the skeletal system, postnatal growth, and the function and viability of the pancreas," Molecular and Cellular Biology, vol. 22, no. 11, pp. 3864-3874, 2002. 
[53] H. P. Harding, Y. Zhang, and D. Ron, "Protein translation and folding are coupled by an endoplasmic- reticulum-resident kinase," Nature, vol. 397, no. 6716, pp. 271-274, 1999.

[54] E. Diakogiannaki and N. G. Morgan, "Differential regulation of the ER stress response by long-chain fatty acids in the pancreatic $\beta$-cell," Biochemical Society Transactions, vol. 36, no. 5, pp. 959-962, 2008.

[55] P. Pirot, F. Ortis, M. Cnop et al., "Transcriptional regulation of the endoplasmic reticulum stress gene chop in pancreatic insulin-producing cells," Diabetes, vol. 56, no. 4, pp. 1069 1077, 2007.

[56] M. G. Hartman, D. Lu, M. L. Kim et al., "Role for activating transcription factor 3 in stress-induced $\beta$-cell apoptosis," Molecular and Cellular Biology, vol. 24, no. 13, pp. 5721-5732, 2004.

[57] D. Li, X. Yin, E. J. Zmuda et al., “The repression of IRS2 gene by ATF3, a stress-inducible gene, contributes to pancreatic $\beta$ cell apoptosis," Diabetes, vol. 57, no. 3, pp. 635-644, 2008.

[58] E. J. Zmuda, L. Qi, M. X. Zhu, R. G. Mirmira, M. R. Montminy, and T. Hai, "The roles of ATF3, an adaptive-response gene, in high-fat-diet-induced diabetes and pancreatic $\beta$-cell dysfunction," Molecular Endocrinology, vol. 24, no. 7, pp. 1423-1433, 2010.

[59] C. J. Huang, C. Y. Lin, L. Haataja et al., "High expression rates of human islet amyloid polypeptide induce endoplasmic reticulum stress-mediated $\beta$-cell apoptosis, a characteristic of humans with type 2 but not type 1 diabetes," Diabetes, vol. 56, no. 8, pp. 2016-2027, 2007.

[60] K. D. McCullough, J. L. Martindale, L. O. Klotz, T. Y. Aw, and N. J. Holbrook, "Gadd153 sensitizes cells to endoplasmic reticulum stress by down-regulating $\mathrm{Bc} 12$ and perturbing the cellular redox state," Molecular and Cellular Biology, vol. 21, no. 4, pp. 1249-1259, 2001.

[61] S. J. Marciniak, C. Y. Yun, S. Oyadomari et al., "CHOP induces death by promoting protein synthesis and oxidation in the stressed endoplasmic reticulum," Genes and Development, vol. 18, no. 24, pp. 3066-3077, 2004.

[62] B. Song, D. Scheuner, D. Ron, S. Pennathur, and R. J. Kaufman, "Chop deletion reduces oxidative stress, improves $\beta$ cell function, and promotes cell survival in multiple mouse models of diabetes," Journal of Clinical Investigation, vol. 118, no. 10, pp. 3378-3389, 2008.

[63] D. A. Cunha, L. Ladrière, F. Ortis et al., "Glucagon-like peptide-1 agonists protect pancreatic $\beta$-cells from lipotoxic endoplasmic reticulum stress through upregulation of BIP and JunB," Diabetes, vol. 58, no. 12, pp. 2851-2862, 2009.

[64] E. Bachar, Y. Ariav, M. Ketzinel-Gilad, E. Cerasi, N. Kaiser, and G. Leibowitz, "Glucose amplifies fatty acid-induced endoplasmic reticulum stress in pancreatic $\beta$-cells via activation of mTORC1," PLoS ONE, vol. 4, no. 3, article e4954, 2009.

[65] F. Urano, X. Wang, A. Bertolotti et al., "Coupling of stress in the ER to activation of JNK protein kinases by transmembrane protein kinase IRE1," Science, vol. 287, no. 5453, pp. 664-666, 2000.

[66] T. Nakagawa, H. Zhu, N. Morishima et al., "Caspase12 mediates endoplasmic-reticulum-specific apoptosis and cytotoxicity by amyloid- $\beta$," Nature, vol. 403, no. 6765, pp. 98-103, 2000.

[67] J. Hirosumi, G. Tuncman, L. Chang et al., "A central, role for JNK in obesity and insulin resistance," Nature, vol. 420, no. 6913, pp. 333-336, 2002.

[68] G. Solinas, W. Naugler, F. Galimi, M. S. Lee, and M. Karin, "Saturated fatty acids inhibit induction of insulin gene transcription by JNK-mediated phosphorylation of insulinreceptor substrates," Proceedings of the National Academy of Sciences of the United States of America, vol. 103, no. 44, pp. 16454-16459, 2006.

[69] J. W. Lee, W. H. Kim, J. Yeo, and M. H. Jung, "ER stress is implicated in mitochondrial dysfunction- induced apoptosis of pancreatic beta cells," Molecules and Cells, vol. 30, no. 6, pp. 545-549, 2010.

[70] M. M. Wasilewski and L. Scorrano, "The changing shape of mitochondrial apoptosis," Trends in Endocrinology and Metabolism, vol. 20, no. 6, pp. 287-294, 2009.

[71] D. C. Chan, "Mitochondria: dynamic organelles in disease, aging, and development," Cell, vol. 125, no. 7, pp. 1241-1252, 2006.

[72] V. P. Bindokas, A. Kuznetsov, S. Sreenan, K. S. Polonsky, M. W. Roe, and L. H. Philipson, "Visualizing superoxide production in normal and diabetic rat islets of Langerhans," Journal of Biological Chemistry, vol. 278, no. 11, pp. 97969801, 2003.

[73] A. J. A. Molina, J. D. Wikstrom, L. Stiles et al., "Mitochondrial networking protects $\beta$-cells from nutrient-induced apoptosis," Diabetes, vol. 58, no. 10, pp. 2303-2315, 2009.

[74] K. S. Park, A. Wiederkehr, C. Kirkpatrick et al., "Selective actions of mitochondrial fission/fusion genes on metabolism-secretion coupling in insulin-releasing cells," Journal of Biological Chemistry, vol. 283, no. 48, pp. 3334733356, 2008.

[75] V. Koshkin, F. F. Dai, C. A. Robson-Doucette, C. B. Chan, and M. B. Wheeler, "Limited mitochondrial permeabilization is an early manifestation of palmitate-induced lipotoxicity in pancreatic $\beta$-cells," Journal of Biological Chemistry, vol. 283, no. 12, pp. 7936-7948, 2008.

[76] S. E. Choi, H. E. Kim, H. C. Shin et al., "Involvement of $\mathrm{Ca}^{2+}-$ mediated apoptotic signals in palmitate-induced MIN6N8a beta cell death," Molecular and Cellular Endocrinology, vol. 272, no. 1-2, pp. 50-62, 2007.

[77] J. Chandra, B. Zhivotovsky, S. Zaitsev, L. Juntti-Berggren, P. O. Berggren, and S. Orrenius, "Role of apoptosis in pancreatic $\beta$-cell death in diabetes," Diabetes, vol. 50, supplement 1 , pp. S44-S47, 2001.

[78] D. Boehning, R. L. Patterson, L. Sedaghat, N. O. Glebova, T. Kurosaki, and S. H. Snyder, "Cytochrome c binds to inositol $(1,4,5)$ trisphosphate receptors, amplifying calciumdependent apoptosis," Nature Cell Biology, vol. 5, no. 12, pp. 1051-1061, 2003.

[79] E. H. Y. Cheng, M. C. Wei, S. Weiler et al., "BCL-2, BCL-XL sequester BH3 domain-only molecules preventing BAX- and BAK-mediated mitochondrial apoptosis," Molecular Cell, vol. 8, no. 3, pp. 705-711, 2001.

[80] G. Kroemer, L. Galluzzi, and C. Brenner, "Mitochondrial membrane permeabilization in cell death," Physiological Reviews, vol. 87, no. 1, pp. 99-163, 2007.

[81] X. Roucou, S. Montessuit, B. Antonsson, and J. C. Martinou, "Bax oligomerization in mitochondrial membranes requires tBid (caspase-8-cleaved Bid) and a mitochondrial protein," Biochemical Journal, vol. 368, pp. 915-921, 2002.

[82] F. Allagnat, D. Cunha, F. Moore, J. M. Vanderwinden, D. L. Eizirik, and A. K. Cardozo, "Mcl-1 down regulation by pro-inflammatory cytokines and palmitate is an early event contributing to $\beta$-cell apoptosis," Cell Death and Differentitiation, vol. 18, no. 2, pp. 328-337, 2011.

[83] H. Liu, H. W. Peng, Y. S. Cheng, H. S. Yuan, and H. F. YangYen, "Stabilization and enhancement of the antiapoptotic 
activity of Mcl-1 by TCTP,' Molecular and Cellular Biology, vol. 25, no. 8, pp. 3117-3126, 2005.

[84] F. Diraison, K. Hayward, K. L. Sanders et al., "Translationally controlled tumour protein (TCTP) is a novel glucoseregulated protein that is important for survival of pancreatic beta cells," Diabetologia, vol. 54, no. 2, pp. 368-379, 2011.

[85] M. Shimabukuro, M. Y. Wang, Y. T. Zhou, C. B. Newgard, and R. H. Unger, "Protection against lipoapoptosis of $\beta$ cells through leptin-dependent maintenance of Bcl-2 expression," Proceedings of the National Academy of Sciences of the United States of America, vol. 95, no. 16, pp. 9558-9561, 1998.

[86] K. D. McCullough, J. L. Martindale, L. O. Klotz, T. Y. Aw, and N. J. Holbrook, "Gadd153 sensitizes cells to endoplasmic reticulum stress by down-regulating $\mathrm{Bc} 12$ and perturbing the cellular redox state," Molecular and Cellular Biology, vol. 21, no. 4, pp. 1249-1259, 2001.

[87] M. C. Bassik, L. Scorrano, S. A. Oakes, T. Pozzan, and S. J. Korsmeyer, "Phosphorylation of BCL-2 regulates ER Ca ${ }^{2+}$ homeostasis and apoptosis," EMBO Journal, vol. 23, no. 5, pp. 1207-1216, 2004.

[88] J. Häcki, L. Egger, L. Monney et al., "Apoptotic crosstalk between the endoplasmic reticulum and mitochondria controlled by Bcl-2," Oncogene, vol. 19, no. 19, pp. 2286-2295, 2000.

[89] R. K. Srivastava, S. J. Sollott, L. Khan, R. Hansford, E. G. Lakatta, and D. L. Longo, "Bcl-2 and Bcl-X(L) block thapsigargin-induced nitric oxide generation, c-Jun NH2terminal kinase activity, and apoptosis," Molecular and Cellular Biology, vol. 19, no. 8, pp. 5659-5674, 1999.

[90] J. L. Contreras, C. A. Smyth, G. Bilbao et al., "Coupling endoplasmic reticulum stress to cell death program in isolated human pancreatic islets: effects of gene transfer of Bcl-2," Transplant International, vol. 16, no. 7, pp. 537-542, 2003.

[91] U. Özcan, E. Yilmaz, L. Özcan et al., "Chemical chaperones reduce ER stress and restore glucose homeostasis in a mouse model of type 2 diabetes," Science, vol. 313, no. 5790, pp. 1137-1140, 2006.

[92] M. Boyce, K. F. Bryant, C. Jousse et al., "A selective inhibitor of elF $2 \alpha$ dephosphorylation protects cells from ER stress," Science, vol. 307, no. 5711, pp. 935-939, 2005.

[93] D. J. Drucker, "Glucagon-like peptide-1 and the islet $\beta$ cell: augmentation of cell proliferation and inhibition of apoptosis," Endocrinology, vol. 144, no. 12, pp. 5145-5148, 2003.

[94] L. Farilla, A. Bulotta, B. Hirshberg et al., "Glucagon-like peptide 1 inhibits cell apoptosis and improves glucose responsiveness of freshly isolated human islets," Endocrinology, vol. 144, no. 12, pp. 5149-5158, 2003.

[95] L. Farilla, H. Hongxiang, C. Bertolotto et al., "Glucagon-like peptide-1 promotes islet cell growth and inhibits apoptosis in Zucker diabetic rats," Endocrinology, vol. 143, no. 11, pp. 4397-4408, 2002.

[96] E. Middleton Jr., C. Kandaswami, and T. C. Theoharides, "The effects of plant flavonoids on mammalian cells: implications for inflammation, heart disease, and cancer," Pharmacological Reviews, vol. 52, no. 4, pp. 673-751, 2000.

[97] E. M. Kurowska and J. A. Manthey, "Hypolipidemic effects and absorption of citrus polymethoxylated flavones in hamsters with diet-induced hypercholesterolemia," Journal of Agricultural and Food Chemistry, vol. 52, no. 10, pp. 28792886, 2004.

[98] K. Takano, Y. Tabata, Y. Kitao et al., "Methoxyflavones protect cells against endoplasmic reticulum stress and neurotoxin,"
American Journal of Physiology-Cell Physiology, vol. 292, no. 1, pp. C353-C361, 2007.

[99] M. Vessal, M. Hemmati, and M. Vasei, "Antidiabetic effects of quercetin in streptozocin-induced diabetic rats," Comparative Biochemistry and Physiology C, vol. 135, no. 3, pp. 357364, 2003.

[100] O. Coskun, M. Kanter, A. Korkmaz, and S. Oter, "Quercetin, a flavonoid antioxidant, prevents and protects streptozotocin-induced oxidative stress and beta-cell damage in rat pancreas," Pharmacological Reviews, vol. 51, no. 2, pp. 117-123, 2005.

[101] D. Liu, W. Zhen, Z. Yang, J. D. Carter, H. Si, and K. A. Reynolds, "Genistein acutely stimulates insulin secretion in pancreatic beta-cells through a cAMP-dependent protein kinase pathway," Diabetes, vol. 55, no. 4, pp. 1043-1050, 2006.

[102] Z. Fu and D. Liu, "Long-term exposure to genistein improves insulin secretory function of pancreatic $\beta$-cells," European Journal of Pharmacology, vol. 616, no. 1-3, pp. 321-327, 2009.

[103] Z. Fu, W. Zhang, W. Zhen et al., "Genistein induces pancreatic $\beta$-cell proliferation through activation of multiple signaling pathways and prevents insulin-deficient diabetes in mice," Endocrinology, vol. 151, no. 7, pp. 3026-3037, 2010. 


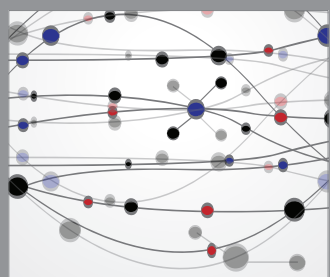

The Scientific World Journal
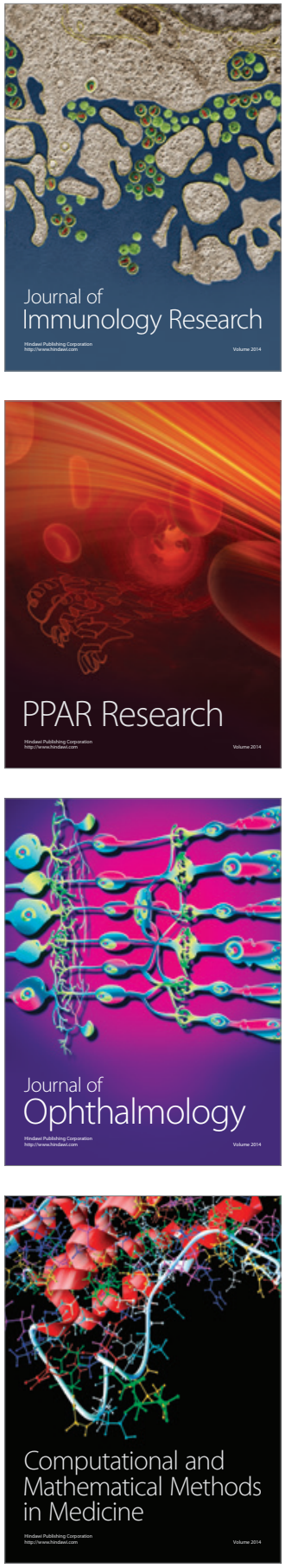

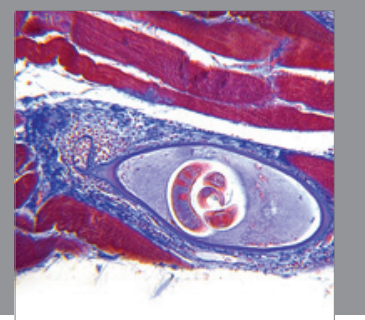

Gastroenterology

Research and Practice
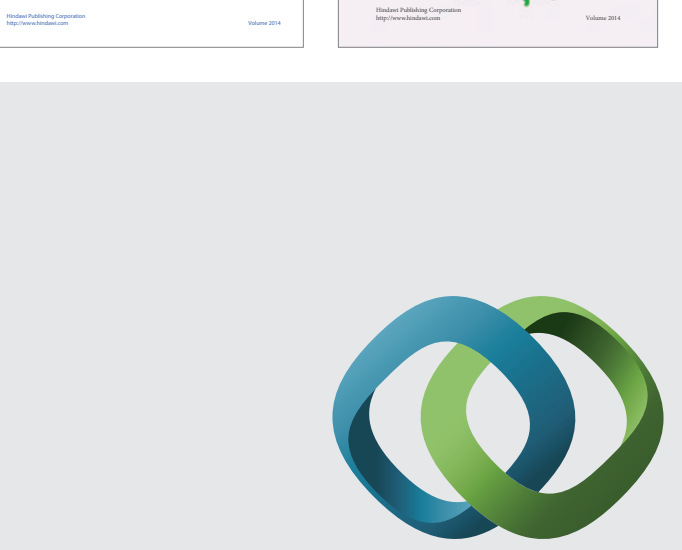

\section{Hindawi}

Submit your manuscripts at

http://www.hindawi.com
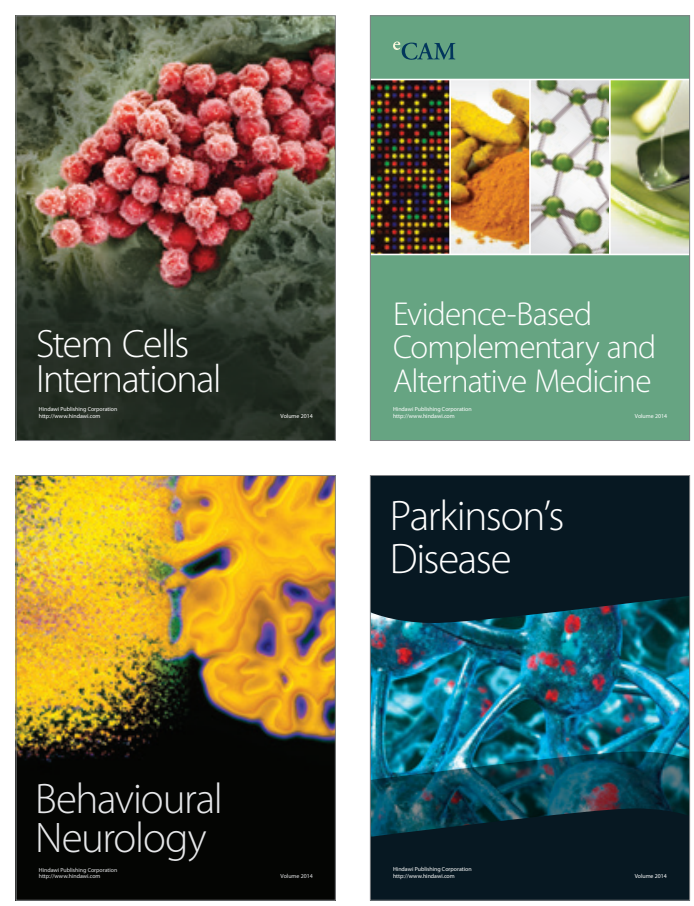

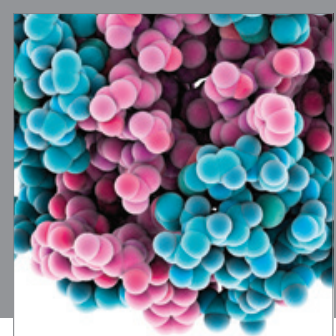

Journal of
Diabetes Research

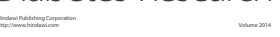

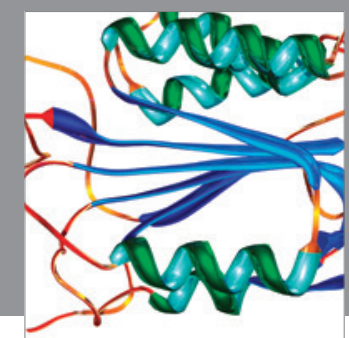

Disease Markers
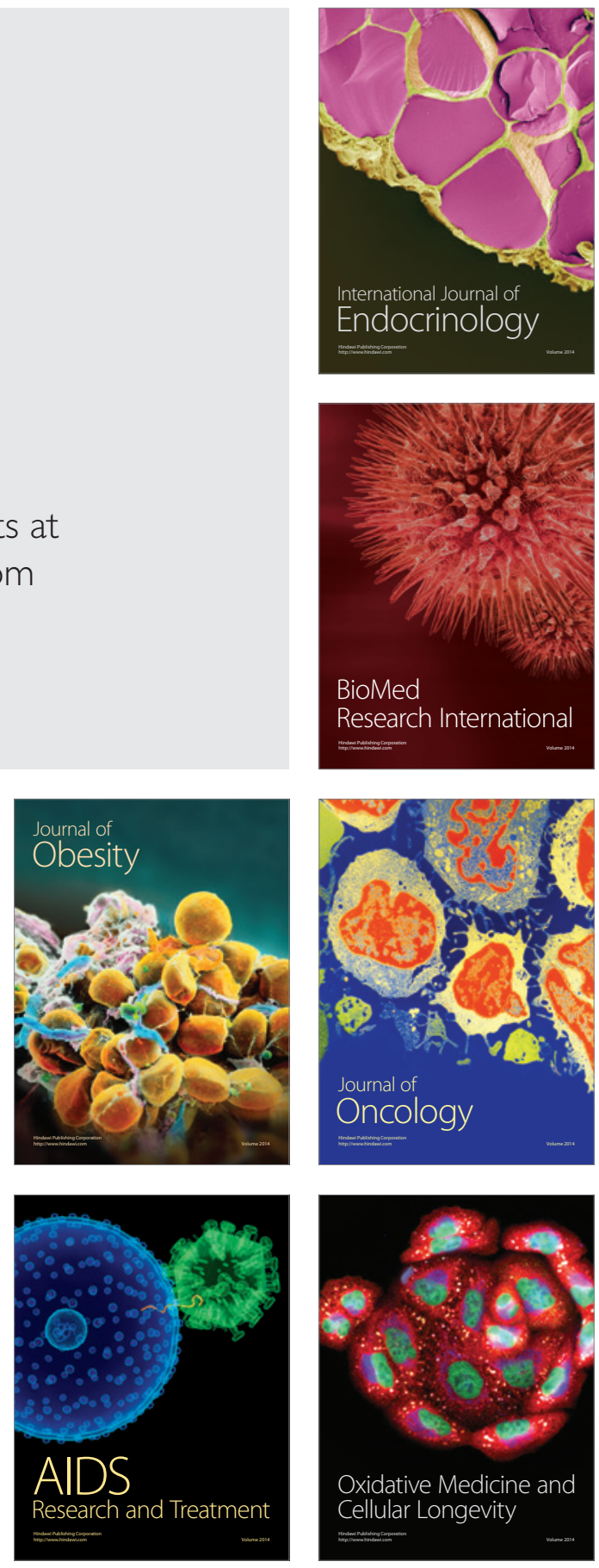